\title{
An Evaluation of Dendroecological Indicators of Snow Avalanches in the Swiss Alps
}

Author(s): Alejandro Casteller, Veronika Stöckli, Ricardo Villalba, and Andrea C. Mayer

Source: Arctic, Antarctic, and Alpine Research, 39(2):218-228.

Published By: Institute of Arctic and Alpine Research (INSTAAR), University of Colorado

DOI: http://dx.doi.org/10.1657/1523-0430(2007)39[218:AEODIO]2.0.CO;2

URL: http://www.bioone.org/doi/full/10.1657/1523-0430\%282007\%2939\%5B218\%3AAEODIO

$\% 5 \mathrm{D} 2.0 . \mathrm{CO} \% 3 \mathrm{~B} 2$

BioOne (www.bioone.org) is a nonprofit, online aggregation of core research in the biological, ecological, and environmental sciences. BioOne provides a sustainable online platform for over 170 journals and books published by nonprofit societies, associations, museums, institutions, and presses.

Your use of this PDF, the BioOne Web site, and all posted and associated content indicates your acceptance of BioOne's Terms of Use, available at www.bioone.org/page/terms_of_use.

Usage of BioOne content is strictly limited to personal, educational, and non-commercial use. Commercial inquiries or rights and permissions requests should be directed to the individual publisher as copyright holder. 


\section{An Evaluation of Dendroecological Indicators of Snow Avalanches in the Swiss Alps}

\author{
Alejandro Casteller*t \\ Veronika Stöckli* \\ Ricardo Villalba† and \\ Andrea C. Mayer* \\ *WSL, Swiss Federal Institute for Snow \\ and Avalanche Research SLF, \\ Flüelastrasse 11, CH-7260 Davos Dorf, \\ Switzerland \\ $\dagger$ Instituto Argentino de Nivología, \\ Glaciología y Ciencias Ambientales \\ IANIGLA, C.C. 330, 5500 Mendoza, \\ Argentina \\ *Corresponding author. \\ casteller@lab.cricyt.edu.ar
}

\begin{abstract}
Avalanche records are important for land-use planning and risk management in mountainous areas. Written records on dates, disturbed area, and pressure patterns of past snow avalanches are scarce. Tree rings can be used to complement written records on past avalanche activity. We conducted two case studies at documented avalanche tracks in the Swiss Alps to determine the most valuable dendroecological indicators for reconstructing past avalanche events. Both tracks were impacted by avalanche events in 1951 and 1999, the two most exceptional avalanche years in recent Swiss history. The difference in tree age among the track, border, run-out, and control sectors was a valuable indicator of the area impacted by past avalanches, but not a useful tool to establish dates of avalanche occurrences. Comparisons of reaction wood formation, changes in stem eccentricity, and presence of traumatic resin canals among sectors showed significantly larger values of these indicators after the 1999 event in the track areas, and in minor degree in the border areas. Abrupt growth changes following the 1999 event were identified in most disturbed trees. Growth releases were commonly accompanied by the formation of reaction wood. Tree-ring evidences for the 1951 avalanche event were limited mainly due to the removal of debris by local communities. The intensity of avalanche events was difficult to determine using tree-ring indicators. Although dates and areas impacted by documented avalanche events were sometimes assessed using single indicators, more precise reconstructions result from the combined use of several dendroecological indicators.
\end{abstract}

\section{Introduction}

Knowledge of snow-avalanche regimes is crucial for human safety in mountain regions. In snow-rich areas such as the Alps, snow avalanches endanger settlements and cause heavy damage to infrastructure every year. In Switzerland, the most destructive avalanches (avalanches and snow avalanches are used synonymously in this paper) that occurred during the winter of 19981999, between 22 and 24 February, caused 17 deaths and damages over 600 million Swiss francs to buildings and roads (Bründl et al., 2004). Therefore, an accurate determination of the zones threatened by avalanches, together with their period of recurrence, is vital for land-use planning and risk management in mountain regions (Gruber and Margreth, 2001).

Avalanche events have been precisely documented for several centuries in settlements across the Alps, especially in Switzerland. Nevertheless, these records are scarce from other areas in the world and cover a limited time span. Tree rings, used as proxy records for snow-avalanche events, provide a useful tool to reconstruct avalanche characteristics with annual resolution (Burrows and Burrows, 1976; Carrara, 1979; Butler and Malanson, 1985). The remaining evidence of avalanche events preserved in the tree-ring sequences varies notably, and primarily depends on (1) the type and size of avalanche, (2) the topography, and (3) treerelated features such as species, tilting degree, diameter, height, and tree age. The first comprehensive description of the potential of tree rings in the study of avalanche dynamics was made in the middle 1970s (Burrows and Burrows, 1976). Disturbances such as tilting, removal of branches, and burial of stems were linked to tree responses such as abrupt changes in growth and reaction wood formation (Shroder, 1978, 1980). Growth suppressions in trees along avalanche tracks are produced after changes in soil moisture (Potter, 1969), diseases, and insect outbreaks following the avalanches (Burrows and Burrows, 1976), reduction of the photosynthetic area due to branch wreckage and foliage loss (Rayback, 1998), and damage to the root system (Gers et al., 2001). On the other hand, releases in radial growth follow increased photosynthetic activity that results from the release of resources (light, water, nutrients) by dead trees nearby (Potter, 1969; Smith, 1973; Carrara, 1979), or by higher moisture content in the ground after avalanche events (Butler, 1979). Methodological limitations to reconstruct past avalanche events from tree rings have also been reported. The loss of evidence of earlier events due to the destructive effect of recent avalanches has been proposed as the major limitation (Carrara, 1979).

We present case studies for two exceptional avalanche years in recent Swiss history: 1951 and 1999, analyzing the type and quantity of evidence preserved in tree-ring sequences from trees affected by these events. We determined differences in mean ages of trees located in different sectors (track, border, run-out, and control areas) of the avalanche tracks. We analyzed and compared among sectors the presence of reaction wood, traumatic resin canals, injuries, as well as changes in tree-ring eccentricity. Finally, we evaluated the dominant patterns of tree growth in response to avalanche events for different tree species and sectors across the avalanche tracks, and linked these growth patterns with the presence of reaction wood events. 


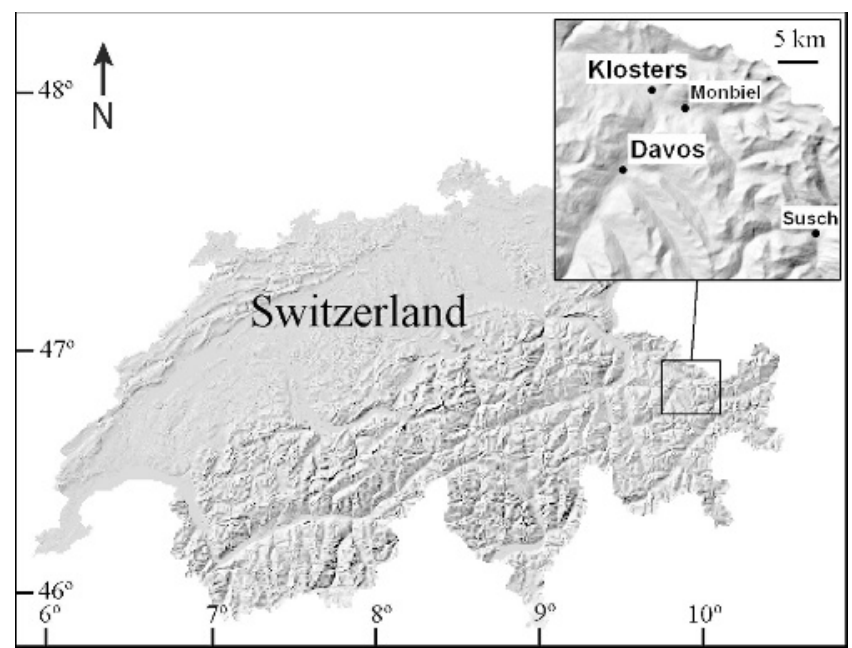

FIGURE 1. Map of Switzerland indicating the location of the study areas.

This study aims to evaluate at two different study sites the accuracy of individual and combined tree-ring indicators to determine the date, area, and intensity of past avalanche events. Ultimately, some of the methodologies and techniques we implement in this study will serve as basic tools to reconstruct past avalanche events in remote areas where no records exist (Bebi et al., 2004), but where developments for recreation and outdoor activities are anticipated.

\section{Material and Methods}

\section{STUDY AREAS AND SAMPLING}

Two study areas were selected: above the village of Monbiel $\left(46^{\circ} 05^{\prime} \mathrm{N}, 9^{\circ} 55^{\prime} \mathrm{E}\right)$ and near the village of Susch $\left(46^{\circ} 43^{\prime} \mathrm{N}\right.$, $10^{\circ} 04^{\prime} \mathrm{E}$ ), both in the Canton of Grisons, Switzerland (Fig. 1). For the two study areas, the dates of the avalanche occurrences have been accurately recorded for the last century. The return period between avalanches is longer than 20 years, and general descriptions of the avalanche features, such as amount of snow and type of avalanche, is also available. In addition to snow avalanches, rockfall events and browsing also affect the growth of trees in these areas. Young average ages in the control areas of both sites are the result of intensive wood utilization by locals in the past. Nearby unmanaged forests reach ages over 200250 years (Bigler and Bugmann, 2004).

\section{Monbiel}

The dominant tree species is Norway spruce (Picea abies L. Karst), which constitutes $90 \%$ of the forest. European larch (Larix decidua Miller), maple (Acer pseudoplatanus L.), and European mountain ash (Sorbus aucuparia L.) are also present. The tree line is located at approximately $1920 \mathrm{~m}$. The parent material is granite gneiss. The slope faces southwest, and the inclination ranges from $25^{\circ}$ to $37^{\circ}$. In 1951 , an avalanche released at $2000 \mathrm{~m}$ with a width at the release area of $150 \mathrm{~m}$ and a total length of approximately $1000 \mathrm{~m}$. In 1999, a new avalanche released at $2600 \mathrm{~m}$, later subdividing into three branches at $2020 \mathrm{~m}$. We surveyed the left branch (looking from below), which coincides with the area affected by the 1951 avalanche (Fig. 2A). The width in the release area and the total length of the 1999 avalanche were approximately $150 \mathrm{~m}$ and $1700 \mathrm{~m}$, respectively. The mean annual temperature at $2140 \mathrm{~m}$ in Klosters, located $3.1 \mathrm{~km}$ from Monbiel, is $1.7^{\circ} \mathrm{C}$ (period 1996-2004; source: SLF measuring data ${ }^{\odot} 2005$, SLF). The mean annual total precipitation for the area, measured at $1200 \mathrm{~m}$, is $1336 \mathrm{~mm}$ (period 1899-2003; source: MeteoSwiss).

We sampled the area in October 2002, including four sectors: the center of the track, along the borders, in the run-out zone, and a control sector located in an unaffected forest $15 \mathrm{~m}$ away from the avalanche track. In each sector, we randomly selected for sampling at least 10 trees with diameters $\geq 3 \mathrm{~cm}$. Trees were sampled independently of external visual damage. Except for a few cases indicated in tables, all samples are from Norway spruce. For trees in the track, cross sections were taken at stem heights between 10 and $50 \mathrm{~cm}$, attempting to capture the presence of reaction wood. For trees showing scars, additional cross sections were removed at the scar height. A relatively large larch was cored in the upper part of the track. This is the only tree older than 100 years located in the avalanche path.

Along the borders, cross sections and wedge sections were taken from small ( $<10 \mathrm{~cm} \mathrm{dbh}$ [diameter at breast height]) and large trees, respectively. Wedge-cut sections were sampled at $100 \mathrm{~cm}$ height to capture growth releases due to improved light conditions. For most trees along the borders, no scars were recorded at the sampling height. In the run-out zone, two

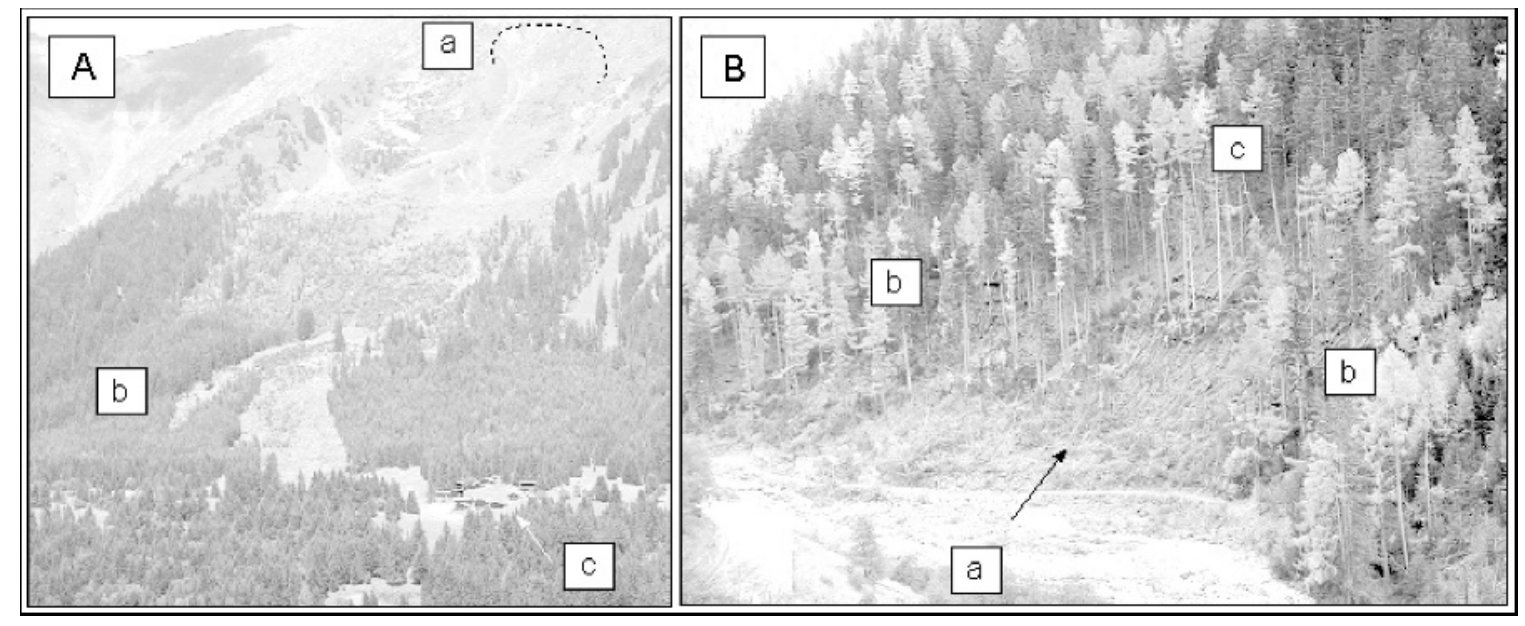

FIGURE 2. (A) Photograph of the Monbiel study site showing the avalanche release (a) and sampling areas (b), adjacent to the Monbiel village (c). (B) At Susch, snow avalanches reach firstly the valley bottom and subsequently the track (a) and border areas (b) to stop in the runout zone (c). Avalanche events at Susch threaten an important road, which is closed in winter to reduce the avalanche-related risk. 
TABLE 1

Trees sampled in different areas at Monbiel. Suppressed (s), co-dominant (cd), and dominant (d) trees were sampled in the control area.

\begin{tabular}{llccccc}
\hline \hline Area & Species & Sampled Trees & Dead trees recorded & Cross sections & Increment cores & Wedge-cut sections \\
\hline Track & P. abies & 26 & 15 & 35 & & 2 \\
& L. decidua & 1 & & 4 & 0 & 10 \\
Border & P. abies & 14 & 1 & $5(\mathrm{~s})$ & $10(5 \mathrm{~cd}, 5 \mathrm{~d})$ & 20 \\
Control & P. abies & 15 & 1 & & 32 & 10 \\
Run-out & P. abies & 10 & 17 & 44 & \\
Total & & 66 & & & \\
\hline
\end{tabular}

increment cores were obtained from each tree at heights ranging from 30 to $40 \mathrm{~cm}$. We sampled a total of 66 trees at Monbiel. Suppressed (s), co-dominant (cd), and dominant trees (d) were sampled in the control area (Table 1). The number of dead trees in $10 \times 20 \mathrm{~m}$ plots was recorded for each sector. Most dead trees lay on the ground with their stems partially or totally broken. Foresters removed the dead wood after the 1951 avalanche, but not after the 1999 event.

Susch

Norway spruce is the dominant tree species $(70 \%)$ near the avalanche track, followed by European larch (20\%). European white birch (Betula pendula Roth) and dwarf mountain pine (Pinus mugo Turra S.L.) are also present at Susch. The parent material is granite gneiss and amphibolite. The tree line is located at $2150 \mathrm{~m}$. The avalanches at this site released on a south-facing slope, reached the valley bottom, and ascended approximately $30 \mathrm{~m}$ on the opposite slope, where we carried out the sampling procedure (Fig. 2B). The angle of the slope ranges between $25^{\circ}$ and $30^{\circ}$. The 1951 avalanche released from $2450 \mathrm{~m}$ elevation and recorded a width of $200 \mathrm{~m}$ at the release area and a total length of $1650 \mathrm{~m}$. In 1999, the avalanche released from $2400 \mathrm{~m}$, had a width at the release area of $400 \mathrm{~m}$, and a total length of $1610 \mathrm{~m}$. Annual mean temperature at Scuol $(1240 \mathrm{~m})$, the closest temperature station to Susch, is $4.99{ }^{\circ} \mathrm{C}$ (period 1901-2003), whereas the mean annual total precipitation from Susch (period 1989-2003) is $754 \mathrm{~mm}$ (source: MeteoSwiss).

The sampling criteria applied in Susch were similar to those used in Monbiel. Seventy-nine trees from three different species were sampled in Susch (Table 2). The control area in this case was located $50 \mathrm{~m}$ away from the avalanche track.

\section{AVALANCHE RECORDS}

In the Swiss Alps, information on avalanche occurrence extends back to the 16 th century in many cases. During the 20th

TABLE 2

Trees sampled in different areas at Susch.

\begin{tabular}{llcccc}
\hline \hline \multirow{2}{*}{ Area } & Species & $\begin{array}{c}\text { Sampled } \\
\text { Trees }\end{array}$ & $\begin{array}{c}\text { Dead trees } \\
\text { recorded }\end{array}$ & $\begin{array}{c}\text { Cross } \\
\text { sections }\end{array}$ & $\begin{array}{c}\text { Increment } \\
\text { cores }\end{array}$ \\
\hline Track & P. abies & 19 & 8 & 22 & \\
& L. decidua & 6 & 3 & 7 & \\
\multirow{5}{*}{ Border } & B. pendula & 4 & & 5 & \\
& P. abies & 25 & & 27 & \\
Control & L. decidua & 3 & 2 & 4 & \\
Run-out & P. abies & 12 & 1 & 13 & \\
& P. abies & 5 & & 0 & 10 \\
Total & L. decidua & 5 & & 0 & 10 \\
\hline
\end{tabular}

century, two winters were marked by intense avalanche activities in the Swiss Alps: 1950-1951 and 1998-1999 (SLF, 1952, 2000; Laternser et al., 1995). At Monbiel, a mixed (powder-flowing) avalanche released naturally on 20 January 1951, destroying approximately 6 ha of forest. At the same site on 21 February 1999, a naturally released slab avalanche affected approximately the same area. At Susch, the 1951 event was on the same day as at Monbiel, whereas the 1999 snow avalanche released on 23 February. The first avalanche at Susch was mixed (powderflowing) and damaged approximately 4.5 ha of forest; the second, powder-slab avalanche damaged an estimated forest area of 5 ha. In all cases, the release area of the avalanches was located above the tree line. No recorded avalanches occurred at our study sites in between the studied events of winters 1950-1951 and 1998-1999. Hereafter for simplification, we will refer to the avalanches that occurred in the winter of 1950-1951 as to the 1951 avalanches, and to the avalanches that occurred in the winter of 1998-1999 as to the 1999 avalanches.

\section{DENDROECOLOGICAL ANALYSES}

The samples obtained in the field were prepared following standard dendrochronological procedures (Stokes and Smiley, 1968). Increment cores were mounted on channeled wood holders and dried before surface preparation. For cores that did not intercept the pith, tree ages were corrected using the methods proposed by Duncan (1989). The number of rings recorded in the cores and cross sections was also corrected for sampling height. For trees ranging between 10 and $100 \mathrm{~cm}$ in height, tree ages were determined at ground level and several points along the stem. By following this procedure on three representative trees from each sector, we estimated the number of missing rings in our samples. Mean tree ages in each sector were calculated based upon these age corrections.

Ring widths were measured to the nearest $0.01 \mathrm{~mm}$, using the Time Series Analysis Program TSAP-Win and the LINTAB measurement device. Two radii located on the up- and down-slope sides of the tree were measured on cross sections. One radius was measured on wedge-cut sections. To detect dating errors (i.e. missing or false rings), tree-ring series were cross-dated, and the quality of the cross-dating was evaluated using the program COFECHA (Holmes, 1983) and the graphical function of the program TSAP-Win. Master tree-ring chronologies from the control sectors were developed using the program ARSTAN (Cook, 1985). These chronologies were used as a reference for cross-dating the samples from other sectors. Depending on sampling ages, the segment length used for comparison in the COFECHA program ranged between 30 and 50 years.

In each cross-dated sample we assessed the following features: (1) the years of reaction wood onset and the number of years with reaction wood (see e.g. Carrara, 1979; Smith et al., 1994), (2) the years with presence of scars (exposed or hidden by the bark) or 
other various damage (see e.g. Mears, 1975; Johnson, 1987) and with traumatic resin canals (see e.g. Cherubini et al., 1997), (3) the years in which abrupt growth changes (suppressions-releases) occurred (Butler, 1985; Rayback, 1998), and (4) changes in eccentricity after the avalanches (see e.g. Carrara, 1979). Microcotome sections $(15-25 \mu \mathrm{m})$ from selected samples facilitated the identification of the above-mentioned anatomical features.

Changes in eccentricity before and after the 1999 avalanche were evaluated using the eccentricity index $(E I)$ :

$$
\begin{aligned}
E I_{1995-1998}= & \sum \text { trw years } 1995-1998 d s r / \\
& \sum \text { trw years } 1995-1998 \text { usr } \\
E I_{1999-2002}= & \sum \text { trw years } 1999-2002 d s r / \\
& \sum \text { trw years } 1999-2002 \text { usr } \\
\Delta E I^{\circ}= & 100^{*}\left(E I_{1999-2002}-E I_{1995-1998}\right) / E I_{1995-1998}
\end{aligned}
$$

where trw is tree-ring width, $d s r$ down-slope radius, $u s r$ up-slope radius, and the subscripts of EI represent the time frame considered. Eccentricity variations and the presence of traumatic resin canals could not be evaluated for the run-out zones due to the poor condition of many cores extracted in these areas.

Dates of tree death were determined by cross-dating the treering series from dead trees against the master chronologies developed from living trees at each of the sampling sites.

\section{STATISTICAL ANAL YSES}

Statistical tests of differences between mean parameters were performed using the Mann-Whitney U-test and the Chi-squared test (Dytham, 2003). A Principal Components Analysis (PCA) (Cooley and Lohnes, 1971) was carried out to identify the dominant patterns in growth responses to the avalanche events at each of the study sites. Tree-ring series from spruce trees were used to determine the dominant responses to the avalanches at Monbiel, whereas ring-width series developed from spruce, larch, and birch trees were separately analyzed for the Susch site. As most of the tree-ring series at Monbiel cover the past three decades, the analysis of the responses to avalanches was limited to the 1999 event. For Susch, tree responses to both the 1951 and 1999 avalanches were studied.

To facilitate the interpretation of the PCA results, the dominant growth pattern (PC1) for each sampling sector was compared with the tree-ring series showing the largest contribution to this pattern. Since interactions between changes in growth patterns and the presence of reaction wood (RW) were expected, we evaluated the sampling direction (up- and down-slope) in combination with the presence of RW events to complement the PCA analyses.

\section{Results}

\section{TREE AGES}

At Monbiel, the mean age of trees in the track was not significantly different from that in the border, but significantly different from mean ages in the other two sectors (Table 3). The mean age of trees in the control area was significantly larger than that in the track. At Susch, the mean tree age in the track differed significantly from mean ages in the other three sectors. Border and control areas showed in this case very similar mean ages (Table 3).
TABLE 3

Mean age $( \pm$ SD) of the trees in the four sampling areas.

\begin{tabular}{lcrcc}
\hline \hline & $\begin{array}{c}\text { Track } \\
(\mathrm{yrs})\end{array}$ & $\begin{array}{c}\text { Border } \\
(\mathrm{yrs})\end{array}$ & $\begin{array}{c}\text { Control } \\
(\mathrm{yrs})\end{array}$ & $\begin{array}{c}\text { Run-out } \\
(\mathrm{yrs})\end{array}$ \\
\hline Site Monbiel & $53^{\mathrm{a}} \pm 7.4$ & $58^{\mathrm{ab}} \pm 4.2$ & $63^{\mathrm{b}} \pm 9.0$ & $71^{\mathrm{c}} \pm 6.8$ \\
Site Susch & $43^{\mathrm{a}} \pm 9.7$ & $53^{\mathrm{b}} \pm 6.3$ & $54^{\mathrm{b}} \pm 3.6$ & $155^{\mathrm{c}} \pm 41.2$ \\
\hline
\end{tabular}

${ }^{a-c}$ Different lowercase superscripts indicate significant differences in age, according to the Mann-Whitney U-test $(P \leq 0.05)$. The results are independent for each study site.

At both study areas, the run-out zones showed significantly larger mean ages than the control areas, especially at Susch. Some trees were older than 50 years, indicating that they survived both the 1999 avalanche and the one that occurred in 1951.

\section{REACTION WOOD EVENTS}

Track and border areas from both Monbiel and Such showed a high proportion of trees with reaction wood (RW) starting in the year 1999 (Table 4). At both sites, the percentage of trees showing RW did not significantly differ between track and border. The values in the control and run-out areas were noticeably lower, with no significant differences between them (Table 4).

The percentage of trees showing RW events in the track and border areas at both sites increased considerably in the year 1999 (Figs. 3 and 6C). RW formation prior to 1999 responded to disturbances other than snow avalanches.

At Monbiel, the number of years with RW since 1999 did not differ significantly between track and border areas (Table 5). The number of years at the control and run-out areas were 0.42 and 0.44 years, respectively, values significantly lower than those in the track and border areas. At Susch, the number of years with RW after 1999 differed significantly between track and border areas (Table 5$)$. Control ( 0.25 years) and run-out ( 0 year) areas showed lower values that significantly differed from tracks and borders, but not between them.

\section{CHANGES IN STEM ECCENTRICITY}

Mean changes in stem eccentricity at the two study sites were larger in the border than within the track areas (Table 6). Nevertheless, the values did not differ significantly due to the large variability in the observations. We compared changes in eccentricity with tree ages (Table 3 ) and stem diameters (Table 7). It is expected that older trees with larger stem diameters show less eccentricity variations after avalanches than younger, smaller trees. At the two study sites, mean age and mean stem diameter values were larger in the border areas compared to the track areas. However, the differences in mean values for these three variables (eccentricity variations, age, and stem diameter) between track and

\section{TABLE 4}

Percentage of Trees with reaction wood formation after the 1999 avalanche events in the four sampling areas.

\begin{tabular}{lcccc}
\hline \hline & Track $(\%)$ & Border $(\%)$ & Control $(\%)$ & Run-out $(\%)$ \\
\hline Site Monbiel & $81^{\mathrm{a}}$ & $78^{\mathrm{a}}$ & $21^{\mathrm{b}}$ & $11^{\mathrm{b}}$ \\
Site Susch & $83^{\mathrm{a}}$ & $92^{\mathrm{a}}$ & $8^{\mathrm{b}}$ & $0^{\mathrm{b}}$
\end{tabular}

${ }^{\mathrm{a}-\mathrm{b}}$ Different lowercase superscripts indicate differences in the percentage of trees with reaction wood, according to the Chi-squared test for contingency tables (1 DF at a level of 5\%). The results are independent for each study site. 


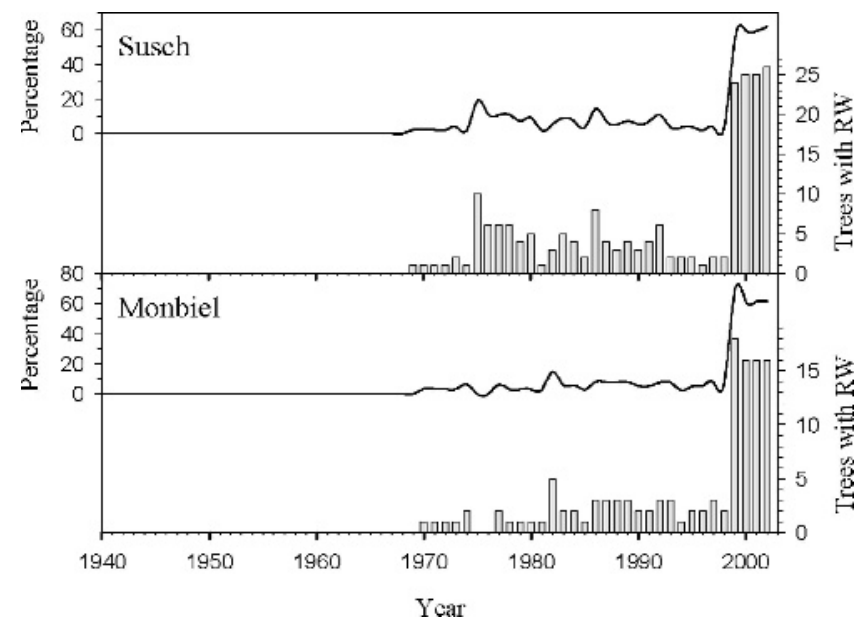

FIGURE 3. Frequency of reaction wood (RW) formation in trees sampled in the track and border areas at Monbiel and Susch. Although RW is recorded at Monbiel before the year 1999, the percentage of trees with RW varies from $10-15 \%$ to over $60 \%$ before and after the 1999 avalanche event, respectively. At Susch, RW percentages range from a maximum of $20 \%$ before 1999 to around $60 \%$ after 1999.

border areas were rarely statistically significant (only the mean age at the Susch site differs for track and border areas). At least five changes in eccentricity directions are observed in a cross section of a spruce tree growing in the track at Monbiel (Fig. 6A). The last change in eccentricity occurred after the avalanche event of 1999.

\section{INJURIES ON TREES CAUSED BY AVALANCHES}

Significant differences in the percentage of injured trees between the track and the other areas were observed at both study sites (Table 8). Under the term injured tree, we considered four different types of damage: (1) scars (visible or hidden), (2) breakage of stems and/or branches, (3) substantial foliage loss, and (4) exposed roots. No significant differences in the percentage of injured trees between the border, control, and run-out areas were recorded at both Monbiel and Susch (Table 8). The percentage of injured trees in the track areas at Monbiel and Susch were $88 \%$ and $65 \%$, respectively.

The frequency of scar formation increased markedly in year 1999 (Fig. 4). No scars from the 1951 avalanche event were preserved in the sampled trees. Besides 1999, scars were also present at both sites in other years (Fig. 4), but with a lower frequency compared to year 1999. In most cases, the date of the scars corresponded either with the onset of RW (Fig. 3) or with the presence of traumatic resin canals (Fig. 5). A spruce tree standing in the avalanche track at Monbiel was severely injured by

TABLE 5

Mean number of years $( \pm S D)$ with reaction wood formation after the 1999 avalanches in the four sampling areas.

\begin{tabular}{lcccc}
\hline \hline & Track (yrs) & Border (yrs) & Control (yrs) & Run-out (yrs) \\
\hline Site Monbiel & $2.90^{\mathrm{a}} \pm 1.70$ & $2.28^{\mathrm{a}} \pm 1.08$ & $0.42^{\mathrm{b}} \pm 1.08$ & $0.44^{\mathrm{b}} \pm 1.33$ \\
Site Susch & $2.38^{\mathrm{a}} \pm 1.41$ & $3.40^{\mathrm{b}} \pm 1.19$ & $0.25^{\mathrm{c}} \pm 0.86$ & $0^{\mathrm{c}}$ \\
\hline
\end{tabular}

${ }^{\mathrm{a}-\mathrm{c}}$ Different lowercase superscripts indicate differences in the mean number of years with RW, according to the Mann-Whitney U-test $(P \leq 0.05)$. The results are independent for each study site.
TABLE 6

Mean changes in stem eccentricity $( \pm$ SD) comparing the periods 1995-1998 and 1999-2002 in the track, border, and control areas.

\begin{tabular}{lccc}
\hline \hline & Track (\%) & Border (\%) & Control (\%) \\
\hline Site Monbiel & $90.0^{\mathrm{a}} \pm 107.7$ & $336.0^{\mathrm{a}} \pm 290.0$ & $35.5^{\mathrm{b}} \pm 88.0$ \\
Site Susch & $53.7^{\mathrm{a}} \pm 37.6$ & $70.4^{\mathrm{a}} \pm 26.3$ & $21.6^{\mathrm{b}} \pm 12.4$ \\
\hline
\end{tabular}

a-b Different lowercase superscripts indicate differences in the mean changes in eccentricity, according to the Mann-Whitney U-test $(P \leq 0.05)$. The results are independent for each study site.

the avalanche event of 1999, as shown on the cross section in Figure 6B.

\section{PRESENCE OF TRAUMATIC RESIN CANALS}

After the year 1999, the percentage of trees at Monbiel with traumatic resin canals (TRC) was higher in the track $(90 \%)$ compared to the border (21\%) (Table 9). Contrary to Monbiel, TRC were lower in the track of Susch $(50 \%)$ in relation to the border $(76 \%)$. However, significant differences in mean values are recorded only for Monbiel. Control areas at Monbiel and Susch presented lower percentages of trees with TRC after 1999 compared to track and border areas (Table 9).

Concurrent with the increased presence of $\mathrm{RW}$ and scars since 1999, TRC also increased in track and border areas at both sites (Fig. 5). At a microscopical level, TRC and resin pockets are observed on a larch cross section sampled in the track at Susch (Fig. 6D).

\section{GROWTH PATTERN VARIATIONS AND THEIR RELATIONSHIP WITH REACTION WOOD FORMATION}

Monbiel

The dominant growth pattern (PC1) of the trees in the track at Monbiel shows an abrupt growth change (AGC; i.e. abrupt variation in radial growth) after the 1999 avalanche (Fig. 7A). In the border (Fig. 7B) the dominant pattern shows a similar trend to that recorded in the track. In contrast, the dominant patterns in the control and run-out areas (Figs. 7C and 7D, respectively) do not record any abrupt changes in tree growth after the 1999 avalanche. In the run-out area, the PC1 shows a continuous decrease in tree growth since 1971 with no AGC following the 1999 avalanche.

Several tree-ring series from the track and border areas at Monbiel that contribute to the PC1 pattern presented RW after 1999. For instance, the three trees with the largest contribution to $\mathrm{PC} 1$ in the border sector showed RW in the down-slope direction after the year 1999 (Fig. 7B). RW after the 1999 event was not recorded in trees along the control and run-out sectors.

\section{TABLE 7}

Mean stem diameters $( \pm$ SD) of the trees in the four sampling areas.

\begin{tabular}{lcccc}
\hline \hline & Track $(\mathrm{cm})$ & Border $(\mathrm{cm})$ & Control $(\mathrm{cm})$ & Run-out $(\mathrm{cm})$ \\
\hline Site Monbiel & $6.85^{\mathrm{a}} \pm 2.86$ & $7.00^{\mathrm{a}} \pm 3.67$ & $18.14^{\mathrm{b}} \pm 8.05$ & $6.92^{\mathrm{a}} \pm 2.03$ \\
Site Susch & $5.73^{\mathrm{a}} \pm 1.62$ & $6.52^{\mathrm{a}} \pm 1.77$ & $11.31^{\mathrm{b}} \pm 3.20$ & $27.71^{\mathrm{c}} \pm 14.2$
\end{tabular}

${ }^{\mathrm{a}-\mathrm{c}}$ Different lowercase superscripts indicate differences in the mean stem diameters, according to the Mann-Whitney U-test $(P \leq 0.05)$. The results are independent for each study site. 


\section{TABLE 8}

Percentage of Injured trees in the four sampling areas.

\begin{tabular}{lcccc}
\hline \hline & Track (\%) & Border (\%) & Control (\%) & Run-out (\%) \\
\hline Site Monbiel & $88^{\mathrm{a}}$ & $14^{\mathrm{b}}$ & $20^{\mathrm{b}}$ & $33^{\mathrm{b}}$ \\
Site Susch & $65^{\mathrm{a}}$ & $17^{\mathrm{b}}$ & $25^{\mathrm{b}}$ & $0^{\mathrm{b}}$ \\
\hline
\end{tabular}

${ }^{a-b}$ Different lowercase superscripts indicate differences in the percentage of injured trees, according to the Chi-squared test for contingency tables(1 DF at a level of $5 \%$ ). The results are independent for each study site.

\section{Susch}

We recorded similar dominant growth patterns for spruce (Fig. 8A) and larch (Fig. 8B) in the track, but different for white birch (Fig. 8C). The spruce and larch dominant patterns (PC1) are characterized by negative trends since 1990 and mid-1970, respectively. In contrast to the previous patterns, an abrupt growth release is observed in the white birch pattern after the 1999 avalanche event. In the border, the dominant growth pattern of spruce trees shows a marked release in growth after the 1999 avalanche (Fig. 8D). In the control area, no detectable growth changes were recorded after the 1999 avalanche for spruce (Fig. 8E). The PCA carried out in the run-out area shows changes in the growth patterns after the 1951 and 1999 avalanche events. Spruce trees show a short-term negative trend in tree growth after both avalanches. Nevertheless, this reduction in tree growth is not abrupt (Fig. 8F). Larch trees show a similar response compared to spruce after the 1999 avalanche, although in this case there is a consistent increase in growth during the four years that followed the avalanche that occurred in 1951 (Fig. 8G).

Similarly to Monbiel, some tree-ring series from trees in the track and border areas at Susch which contribute to the PC1 pattern show RW formation after the year 1999. The trees from the run-out and control sectors did not show RW events for this year. In the track, tree-ring series included in the PC1 with changes in growth after the 1999 event were taken from down- and upslope directions in similar proportions and growth changes were not always related to RW formation (Figs. 8A to 8C). Among the tree-ring series in the track area, the birch trees had the most abrupt growth changes after 1999 (Fig. 8C). The spruce samples from the border area included in the PC1 are from an up-slope

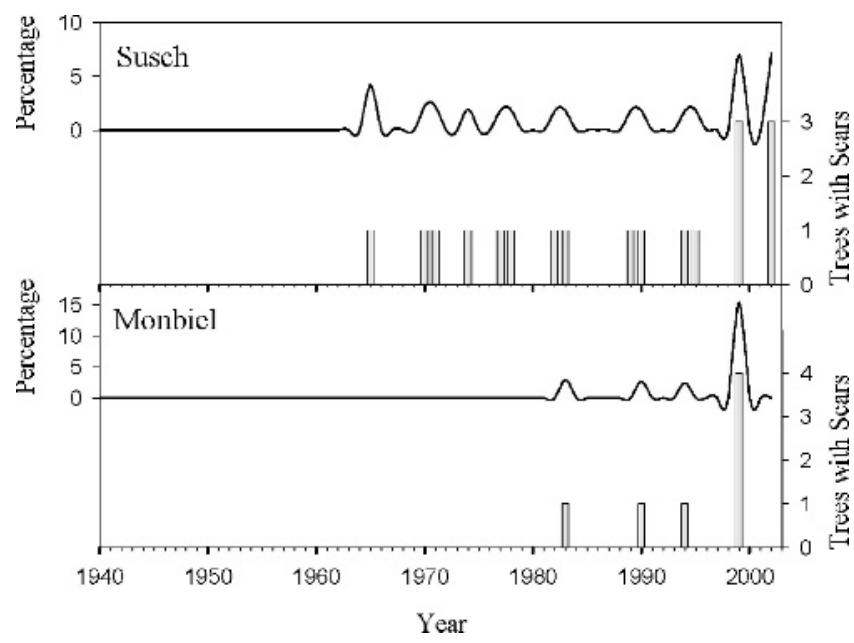

FIGURE 4. Frequency of scar formation on the trees sampled in the track and border areas at Monbiel and Susch. At Monbiel, scars in year 1999 were found in $\mathbf{1 5 . 3} \%$ of the trees. At Susch, $7 \%$ of the trees were scarred by the 1999 avalanche event.

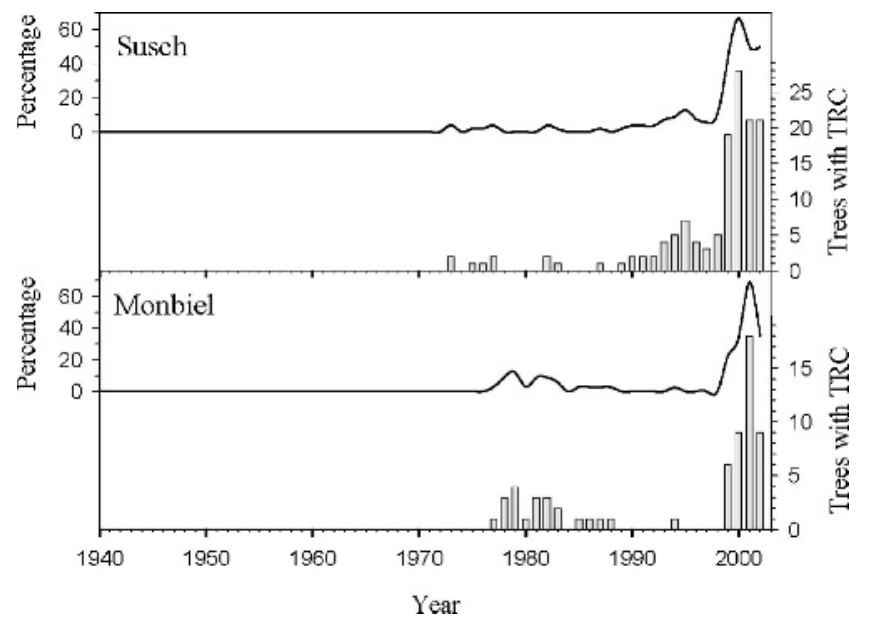

FIGURE 5. Frequency of traumatic resin canals (TRC) on the trees sampled in the track and border areas at Monbiel and Susch. At Monbiel, 23\% of the trees show TRC in year 1999, reaching a peak of $69.2 \%$ in 2001 . At Susch, $44.1 \%$ of the trees show TRC in the year 1999 and the largest value of $66 \%$ scarred trees was recorded in year 2000. Before 1999, the largest value recorded at both sites did not exceed $12 \%$ of the trees.

direction and two of them presented RW events in the year 1999 (Fig. 8D), indicating that not all abrupt growth changes are accompanied by RW formation. In contrast, the tree-ring series from the control area which most contribute to the dominant pattern were taken from the down-slope direction (Fig. 8E), whereas in the run-out zone they are up-slope samples (Figs. 8F and $8 \mathrm{G}$ ). The samples which most contribute to the dominant growth patterns in the control and run-out areas do not show RW formation after the year 1999.

\section{Discussion}

The case studies on the various anatomical, morphological and age-related vegetational features indicative of snow-avalanche events we present in this paper confirm many findings of previous investigations and provide insights on which dendroecological indicators are the most useful for reconstructing past avalanche dynamics. The event date and affected area of documented snow avalanches were accurately reconstructed using individual and combined dendroecological indicators.

Differences in mean ages between different sampling areas are valuable indicators for distinguishing spatial parameters of the forest in relation to past avalanches, but they were not useful to validate the occurrence dates of the1951 and 1999 documented avalanche events. A large proportion of trees in the track, border, and run-out areas survived both events, providing older ages than the number of years passed since these events. This limitation would result in larger estimation errors in sites with short periods of avalanche returns or where avalanches have low destructive power. In the control areas, mean tree ages were found to be considerably younger than expected, which is due to past forest practices in the region.

Trees killed by the 1951 avalanche events were not found in the tracks of Monbiel or Susch. Tree wood decay (Luckman and Frazer, 2002) and the extraction of dead wood by local farmers can explain the lack of tree remains from the 1951 avalanche. In contrast, trees killed by the 1999 avalanche events still remain in situ along both tracks. Not all of these trees died immediately after 


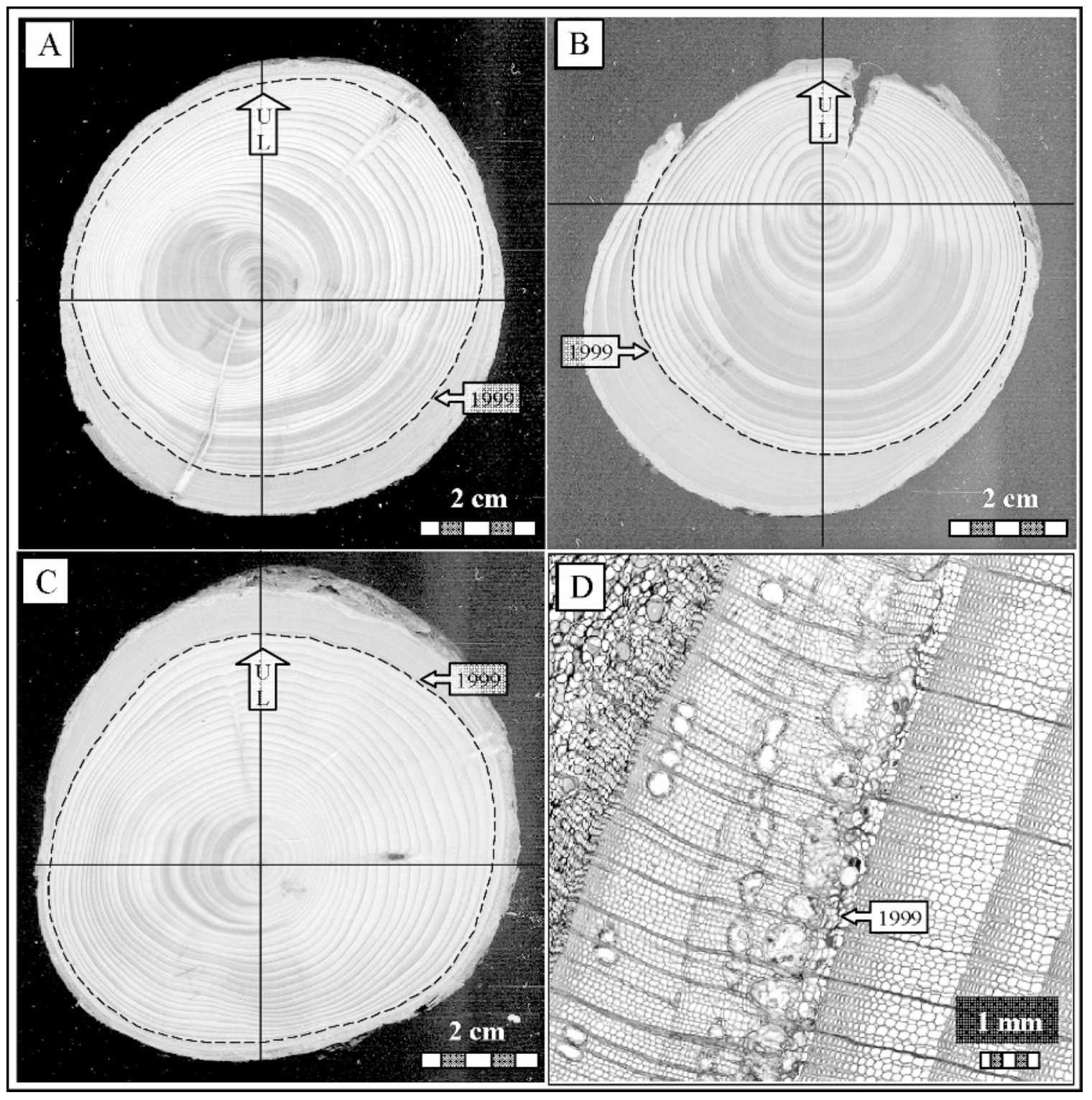

FIGURE 6. (A) Five episodes of eccentricity changes recorded on a spruce cross section from the border at Monbiel. The last change (doted line) was induced by the 1999 avalanche event. "UL" indicates the up-hill side of the stem. (B) Scar formed on the up-hill side of a spruce tree sampled in the track at Monbiel. The date of the scar (1999) coincides with the onset of RW on the opposite side of the stem. (C) A cross section of a spruce tree sampled in the track at Susch showing low-intensity RW formation in the down-slope direction in most rings. A change in the orientation of RW occurred in 1999, due to the down-hill impacting avalanche event. (D) Changes in larch tree growth patterns after the 1999 avalanche. Narrow rings in 1999 and 2000 start to widen after 2001. Traumatic resin canals and resin pockets are indicated by arrows. They are abundant in 1999 and decrease in 2002.

the disturbance. Some trees showed extremely reduced growth the years following the event and before death.

Combined analyses of changes in stem eccentricity and RW formation provide accurate information on past avalanche dates

\section{TABLE 9}

Percentage of Trees with traumatic resin canals after 1999 in the track, border, and control areas.

\begin{tabular}{lccc}
\hline \hline & Track (\%) & Border (\%) & Control (\%) \\
\hline Site Monbiel & $90^{\mathrm{a}}$ & $21^{\mathrm{b}}$ & $21^{\mathrm{b}}$ \\
Site Susch & 50 & $76^{\mathrm{a}}$ & $25^{\mathrm{b}}$ \\
\hline
\end{tabular}

${ }^{\mathrm{a}-\mathrm{b}}$ Different lowercase superscripts indicate differences in the percentage of trees with traumatic resin canals, according to the Chi-squared test for contingency tables (1 DF at a level of 5\%). The results are independent for each study site. and impacted area. In addition to avalanches, variations in stem eccentricity may result from uneven distributions of moisture and nutrients or from unequal developments of crown and root systems. However, stem eccentricity induced by these factors is generally not accompanied by RW formation (Braam et al., 1987). RW is also produced by a variety of processes other than snow avalanches including snow load, wind, soil creep, snow creep and slumps (Carrara, 1979). Therefore, the best estimations of past avalanche activities result from a combined approach using both indicators. In our study, eccentricity changes are larger in the border than in the track areas. Trees in the tracks were observed to grow in a markedly more tilted position compared to the trees in the border areas. The stunted-like growth shape of trees in the track areas results in a reduction of tree resistance to the pass of the avalanches and also in the magnitude of the avalanche-induced stem eccentricity. 

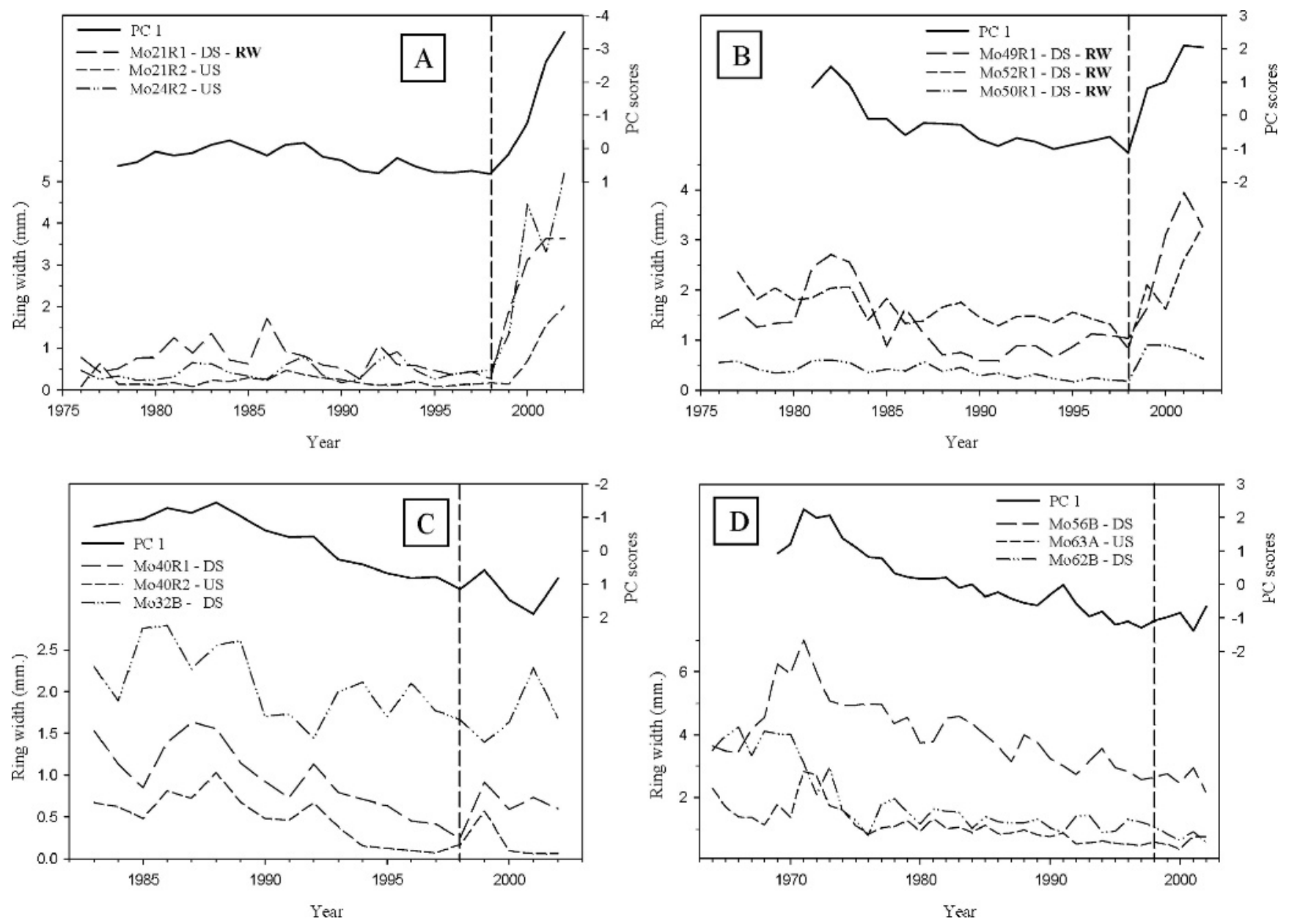

FIGURE 7. Dominant growth patterns (PC1) of spruce at Monbiel, together with the tree-ring series that most contribute to this pattern. The vertical dotted lines indicate the tree ring formed before the avalanche event. The total variance explained by $\mathrm{PC} 1$ is $42.5 \%, 40.4 \%$, $29.8 \%$, and $34.6 \%$ for the track (A), border (B), control (C), and run-out (D) areas, respectively. Sampling directions (DS: down-slope, US: upslope) and the presence of reaction wood (RW) are indicated for each series.

The number of tree rings with presence of RW after the event could be used as an index to characterize the intensity of avalanches. Intensity stands here for avalanche impact pressure and velocity. Previous studies have used vegetation features such as mean stem diameters and modulus of rupture of different tree species, together with depth flow of avalanches, to estimate their intensities (Mears, 1975; Butler, 1979). Other non-vegetational quantitative measurements of avalanche impact forces have been carried out in instrumented avalanche tracks at different locations worldwide (Luckman, 1977). At our sites, the number of tree rings with RW after the year 1999 in the track and border areas represented between 2.2 and 3.4 years. These values could provide some information on the relative intensity of avalanches. However, as the avalanche velocities and impact pressures were not measured, a relationship between $\mathrm{RW}$ and avalanche intensity cannot be established. At sites with short avalanche return periods (less than 5 to 10 years), the use of RW as a measure of avalanche intensity could also produce confusing results. Physiological responses of trees may persist for several years after an avalanche, masking subsequent damage to the same tree (Burrows and Burrows, 1976). Evidently, if several avalanche events occur in the same winter, it would not be possible to estimate the intensity of each event by analyzing RW formation.

The track areas at both sites had a high proportion of trees with visible (external) damage resulting from the 1999 avalanche event. Morphological external damage is accompanied by an increase in the number of trees with scars and traumatic resin canals (TRC) in the wood. However, scars and TRC were also observed before 1999. Previous studies (Burrows and Burrows, 1976; Rayback, 1998) indicate that rockfalls, sun scalds, frost damage, and browsing by animals are also related to scar and TRC formation. Rockfalls and browsing are common at our study sites. In addition, it has been observed that scar-based chronologies provide in some cases a minimum number of the total recorded snow avalanche events (Veblen et al., 1994). Seasonality of scar formation can be estimated based upon the scar position within the annual band. Hence, avalanche scars produced in winter can be differentiated from scars originated from events during the growing season. In the trees along the track areas, scars related to the 1999 event were produced in winter, i.e. before early wood formation. Scars in previous and subsequent years were observed to occur mostly at times of active cambium in late spring and summer. Evidence for eccentricity changes, reaction wood formation, scars, or traumatic resin canals related to the 1951 avalanche event were not recorded mainly due to the lack of available wood remains from that event.

A large number of trees impacted by the 1999 avalanche event recorded abrupt growth changes (AGC) following this event. Positive growth changes in 1999 were commonly accompanied by the formation of reaction wood. At Susch, occasional avalanche 

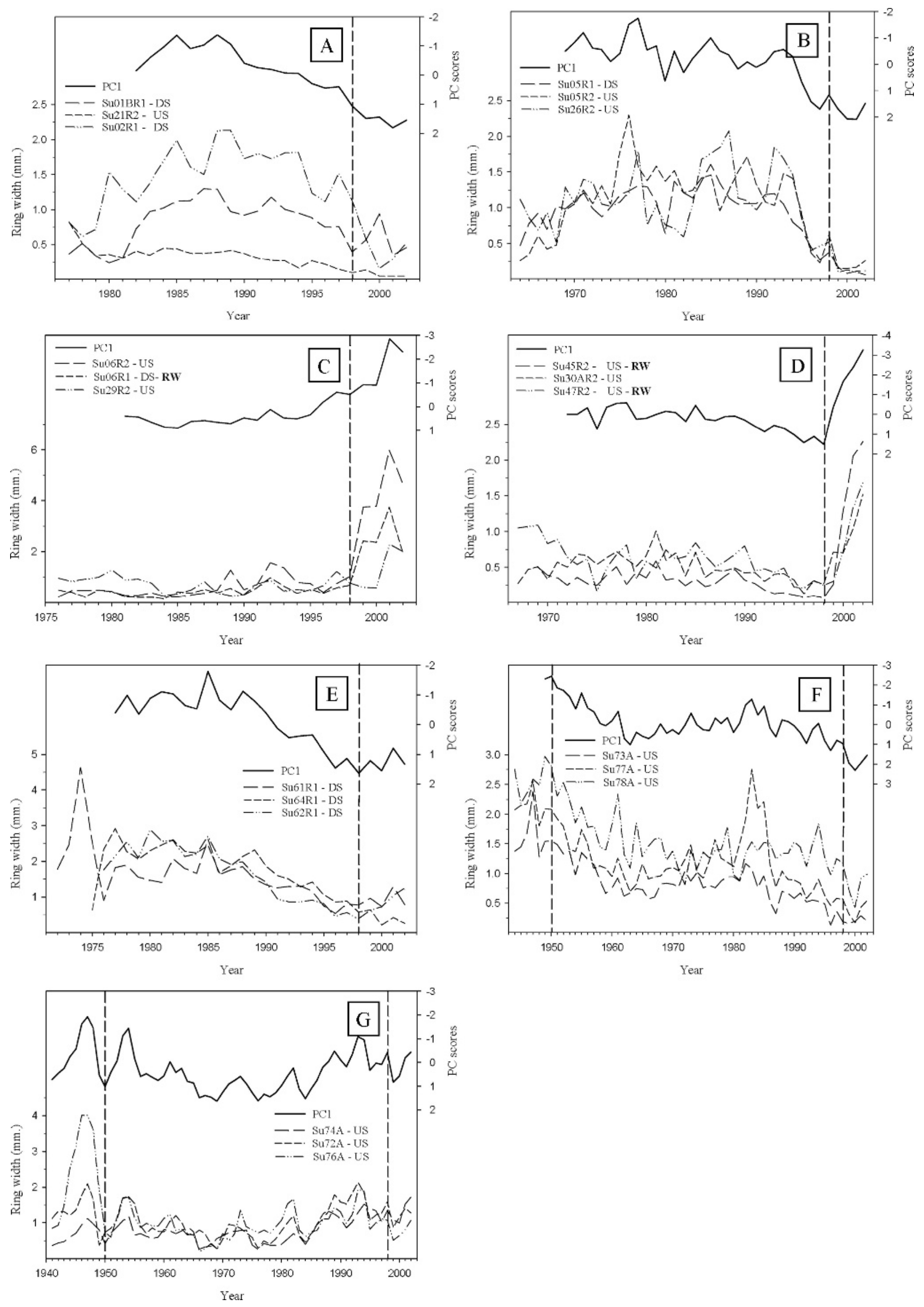

226 / Arctic, Antarctic, And Alpine Research 
events with downslope toward upslope directions induce the RW formation in the upslope side of stems, creating particular patterns of AGC-RW interactions. Upslope increases in ring widths are not always accompanied by RW formation (Fig. 8D). Combined analyses of growth changes and RW on many $(>4)$ radii of the same cross section provide additional information on avalanche events. This multi-feature approach is needed in sites where new avalanche records need to be developed and the searched tree-ring signals are "hidden" or not very notorious in the forests.

\section{Conclusions}

Evaluating the potential of individual and combined dendroecological indicators for reconstructing dates, affected area and intensity of documented avalanche events, allows us to conclude the following: (1) Tree ages in different avalanche sectors (track, borders, run-out, and control area) are useful to demarcate the forest area disturbed by past events, but not to determine event dates. Cross-dating samples from avalanche-killed trees provide precise dates of avalanche occurrences. (2) Combined analyses of changes in stem eccentricity and reaction wood formation provide information on event date and affected area. Although persistence of RW formation could be related to avalanche intensity, in situ measurements of intensity are needed to establish a clear relationship between these two variables. In addition, short periods of avalanche returns may complicate the estimation of past event intensities. (3) Scar formation is often followed by the presence (or increase in the number) of traumatic resin canals. Scars and traumatic resin canals provide additional information on event dates and help to demarcate affected areas. Disturbances such as rockfalls and browsing by animals also induce the formation of scars and traumatic resin canals. However, they are less frequent and more randomly distributed in the disturbed area. (4) The presence of abrupt growth changes is a common feature in avalanche-disturbed trees, principally in the track and border areas. Abrupt growth changes are commonly accompanied by the formation of reaction wood. Although one single dendroecological indicators can provide information on past events, consistent reconstructions of avalanche dynamics rely on a combination of two or more wood indicators.

\section{Acknowledgments}

We are grateful to the reviewers for their valuable comments on a former version of this paper, and to Dr. Fritz $\mathrm{H}$. Schweingruber for his valuable advices. This investigation was financially supported by the Swiss Federal Institute for Snow and Avalanche Research SLF and CONICET, Argentina.

\section{References Cited}

Bebi, P., Casteller, A., Mayer, A. C., and Stöckli, V., 2004: Jahrringe als Indikatoren für extreme Standortsbedingungen im Gebirge: Schnee, Lawinen, und Permafrost. Swiss Forestry Journal, 155: 208-212.
Bigler, C., and Bugmann, H., 2004: Predicting the time of tree death using dendrochronological data. Ecological Applications, 14: 902-914.

Braam, R. R., Weiss, E. E. J., and Burrough, P. A., 1987: Spatial and temporal analysis of mass movement using dendrochronology. Catena, 14: 573-584.

Bründl, M., Etter, H. J., Steiniger, M., Klinger, C., Rhyner, J., and Ammann, W. J., 2004: IFKIS - A basis for managing avalanche risk in settlements and on roads in Switzerland. Natural Hazards and Earth System Sciences, 4: 257-262.

Burrows, C. J., and Burrows, V. L., 1976: Procedures for the study of snow avalanche chronology using growth layers of woody plants. Boulder: Institute of Artic and Alpine Research, University of Colorado, Occasional Paper 54.

Butler, D. R., 1979: Snow avalanche path terrain and vegetation, Glacier National Park, Montana. Arctic and Alpine Research, 11: $17-32$.

Butler, D. R., 1985: Vegetational and geomorphic change on snow avalanche paths, Glacier National Park, Montana, USA. Great Basin Naturalist, 45: 313-317.

Butler, D. R., and Malanson, G. P., 1985: A reconstruction of snow-avalanche characteristics in Montana, USA, using vegetative indicators. Journal of Glaciology, 31: 185-187.

Carrara, P. E., 1979: The determination of snow avalanche frequency through tree-ring analysis and historical records at Ophir, Colorado. Geological Society of America Bulletin, 90: 773-780

Cherubini, P., Schweingruber, F. H., and Forster, T., 1997: Morphology and ecological significance of intra-annual radial cracks in living conifers. Trees Structure and Function, 11: 216-222.

Cook, E. R., 1985: A time series analysis approach to tree-ring standardization. Ph.D. dissertation. University of Arizona: Tucson,

Cooley, W. W., and Lohnes, P. R., 1971: Multivariate data analysis. New York: Wiley \& Sons, 364 pp.

Duncan, R. P., 1989: An evaluation of errors in tree age estimates based on increment cores in kahikatea (Dacrycarpus dacrydioides). New Zealand Natural Sciences, 16: 31-37.

Dytham, C., 2003: Choosing and using statistics: a biologist's guide. Second edition. Malden, Massachusetts: Blackwell Publishing, 248 pp.

Gers, E., Florin, N., Gärtner, H., Glade, T., Dikau, R., and Schweingruber, F., 2001: Application of shrubs for dendrogeomorphological analysis to reconstruct spatial and temporal landslide movement patterns. A preliminary study. Zeitschrift für Geomorphologie N.F., 125: 163-175.

Gruber, U., and Margreth, S., 2001: Winter 1999: a valuable test of the avalanche-hazard mapping procedure in Switzerland. Annals of Glaciology, 32: 328-332.

Holmes, R. L., 1983: Computer-assisted quality control in treering dating and measurement. Tree-Ring Bulletin, 43: 69-75.

Johnson, E. A., 1987: The relative importance of snow avalanche disturbance and thinning on canopy plant populations. Ecology, 68: 43-53.

Laternser, M., Lentner, S., Meier, R., Schneebeli, M., and Utelli, H., 1995: Dokumentation zur Schadenlawinen-Datenbank (SLDB) [Documentation for the Destructive Avalanches Database $(D A D B)]$. Weissfluhjoch-Davos: Eidgenössisches Institut für Schnee- und Lawinenforschung, Interner Bericht Nr. 690 pp.

FIGURE 8. Dominant growth patterns (PC1) of spruce, larch, and white birch at Susch, together with the tree-ring series that most contribute to these patterns. The vertical dotted lines indicate the tree ring formed before the avalanche event. The total variance explained by PC1 is $41.4 \%, 51.9 \%$, and $41.9 \%$ for spruce (A), larch (B), and white birch (C) in the track, respectively; 35.3\% for spruce in border (D); $\mathbf{5 5 . 5} \%$ for spruce in the control area (E) ; and $\mathbf{5 7 . 7 \%}$ and $\mathbf{6 0 . 0} \%$ for spruce (F) and larch (G) in the run-out area, respectively. Sampling directions (DS: down-slope, US: up-slope) and the presence of reaction wood (RW) are indicated for each series. 
Luckman, B. H., 1977: The geomorphic activity of snow avalanches. Geografiska Annaler, 59A: 31-48.

Luckman, B. H., and Frazer, G. W., 2002: Dendrogeomorphic investigations of snow avalanche tracks in the Canadian Rockies., International Conference "Tree Rings and People" in Davos: Switzerland, Poster presentation.

Mears, A. I., 1975: Dynamics of dense snow avalanches interpreted from broken trees. Geology, 3: 521-523.

Potter, N., 1969: Tree-ring dating of snow avalanche tracks and the geomorphic activity of avalanches, northern Absaroka Mountains, Wyoming. Geological Society of America Special Paper, 123: 141-165.

Rayback, S. A., 1998: A dendrogeomorphological analysis of snow avalanches in the Colorado Front Range, USA. Physical Geography, 19: 502-515.

Shroder, J. F., 1978: Dendro-geomorphological analysis of mass movement on Table Cliffs Plateau, Utah. Quaternary Research, 9: $168-185$.

Shroder J, F., 1980: Dendrogeomorphology: review and new techniques of tree-ring dating. Progress in Physical Geography, 4: $161-188$.
SLF, 1952, Schnee und Lawinen in den Schweizer Alpen, Winter 1950/51. Davos, Switzerland: Eidg. Institut für Schnee- und Lawinenforschung, Winterbericht $\mathrm{n}^{\circ} 31$.

SLF, 2000, Der Lawinenwinter 1999. Ereignisanalyse. Davos, Switzerland: Eidg. Institut für Schnee und Lawinenforschung, $588 \mathrm{pp}$.

Smith, D. J., McCarthy, D. P., and Luckman, B. H., 1994: Snowavalanche impact pools in the Canadian Rocky Mountains. Arctic and Alpine Research, 26: 116-127.

Smith, L., 1973: Indication of snow avalanche periodicity through interpretation of vegetation patterns in the North Cascades, Washington. Unpublished M.S. thesis. University of Washington: Seattle.

Stokes, M. A., and Smiley, T. L., 1968: An introduction to tree ring dating. Chicago: University of Chicago Press, 73 pp.

Veblen, T. T., Hadley, K. S., Nel, E. M., Kitzberger, T., Reid, M., and Villalba, R., 1994: Disturbance regime and disturbance interactions in a Rocky Mountain sub-alpine forest. Journal of Ecology, 82: 125-135.

Ms accepted October 2006 